Review

\title{
Double free flaps in oral cavity and oropharynx reconstruction: Systematic review, indications and limits
}

\author{
Giuditta Mannelli $^{\mathrm{a}, *}$, Luca Gazzini ${ }^{\mathrm{b}}$, Lara Valentina Comini ${ }^{\mathrm{c}}$, Giampiero Parrinello ${ }^{\mathrm{d}}$, \\ Riccardo Nocini ${ }^{\mathrm{b}}$, Daniele Marchioni ${ }^{\mathrm{b}}$, Gabriele Molteni ${ }^{\mathrm{b}}$ \\ ${ }^{a}$ Head and Neck Oncology and Robotic Surgery, Department of Experimental and Clinical Medicine, University of Florence, Florence, Italy

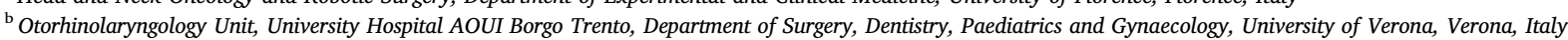 \\ c Otorhinolaryngology Unit, Department of Experimental and Clinical Medicine, University of Florence, Florence, Italy \\ ${ }^{\mathrm{d}}$ IRCCS Ospedale Policlinico San Martino, Genoa, Italy
}

\section{A R T I C L E I N F O}

\section{Keywords:}

Free flaps

Head and neck reconstruction

Composite defects

Double flaps

Free flap indication

\begin{abstract}
A B S T R A C T
The simultaneous use of two different free flaps, harvested from distinct donor sites, has demonstrated a reasonable degree of safety and success rates in head and neck composite defects reconstruction. Unfortunately, their relatively low frequent use, together with the lack of proper statistics on their management strategies, make their indications weak of robust conclusions to better define their role in common practice. The aim of the present study was to review the literature of the last 15 years regarding simultaneous free flap transposition, presenting advantages, disadvantages, and results of this technique, with the final purpose to propose an up-todate panorama for the use of double free flap for complex head and neck defects reconstruction.

Depending on which factors are present, surgeons may choose to select an approach that is theoretically safer, but yields less-than-ideal functional outcomes, such as local flap. Two free flaps may be necessary when the defect contains both a large, complex bony defect, large soft tissue needs, and proper surgical planning and meticulous monitoring continues to be the cornerstone of success.
\end{abstract}

\section{Introduction}

Resection of head and neck tumours can lead to complex and composite defects, which may encompass multiple functional regions (i.e.: face, oral cavity, or pharynx), by involving different tissues such as the mandibular or maxillary bone, soft tissues, facial skin or oral mucosa [1-6]. In addition, essential functions such as chewing, swallowing, and communication might be severely impaired. In this setting, reconstruction goals are increasingly focused on maintaining a satisfactory quality of life for the patient, by restoring both functional and aesthetic outcomes $[1-3,5,6]$.

In the past, the extent of resection would have limited the surgical indication despite potential tumour resectability [2].

In common practice, the use of a single free flap could be insufficient to accomplish surgeons' goals, often defect volume, dimension and its tissue variability, and drive the reconstructive option selection [1-6]; though, to date, free microvascular flaps represent the gold standard treatment for composite head and neck defects reconstruction, due to the fact that they allow surgeons to push the boundaries of safe surgical resection while ensuring good functional results $[1,5]$. In this setting, even the simultaneous use of two different free flaps, harvested from distinct donor sites, has been well described by different authors and they have demonstrated a reasonable degree of safety and success rates [1-6]. On the other hand, it does represent a major procedure, and by itself may arguably have some disadvantages such as requiring prolonged operating time, increasing surgical stress in patients in poor general condition or with concomitant medical problems, and it might enclose technical difficulties as securing two adequate pairs of recipient vessels and performing two sets of anastomosis. Moreover, further scepticism could rise in case of patients who have previously underwent surgery or radiation therapy $[1,5,6]$.

In this scenario, albeit free tissue transfer is technically difficult, overall success rates are reported in literature to be as high as $97 \%$ [7], but theories and statistics on proper double free flaps management strategies and indications still need more robust conclusions to better define their role in common practice. The relatively low frequency of double free flaps use makes it difficult for single institutions to design randomized controlled trials comparing different interventions and

\footnotetext{
* Corresponding author at: Head and Neck Oncology and Robotic Surgery, Department of Experimental and Clinical medicine, University of Florence, Azienda Ospedaliero-Unievrsitaria Careggi, Largo Brambilla 3, CAP 50134 Firenze, Italy.

E-mail address: giuditta.mannelli@unifi.it (G. Mannelli).
} 
indications, and thus we aimed to summarize the most relevant and current evidence surrounding their management through a rigid method of literature analysis. Specifically, the aim of the present study was to review the literature of the last 15 years regarding simultaneous free flap transposition, presenting advantages, disadvantages, and results of this technique, with the final purpose to propose an up-to-date panorama for the use of double free flap for complex head and neck defects supported by a novel algorithm of reconstruction.

\section{Materials and methods}

The systematic review was performed using independently developed search strategies in literature review methodology, and it was written in accordance with PRISMA Statement, to guarantee a scientific strategy of research to limit bias by a systematic assembly, critical appraisal, and synthesis of all the most relevant studies published on this topic. The databases interrogated included PubMed and Cochrane library. Reference lists from identified articles were searched and crossreferenced to identify additional relevant articles. The search terms included the following various combinations to maximize the yield: Double Free Flaps AND Head and Neck Reconstruction AND (Oromandibular OR Oro-cervical) Defects. The search was performed for the first time on April 2019, and it was set to automatically update periodically until August 2019. First, duplicates were removed electronically. Then, abstracts were reviewed to exclude obviously irrelevant articles. Non-English language papers, experimental studies, technical notes, review, and meta-analysis articles were excluded. The inclusion criteria were set a priori and deliberately kept wide to encompass as many articles as possible without compromising the validity of the results, and they included articles: (1) Published from 2004 onwards; (2) Reporting published case or series regarding double free flap use for reconstruction of complex oro-mandibular and oro-cervical defects; (3) Distinguishing defect localization (i.e.: mandibular, retro-molar trigone, hard palate, etc...) and its etiology (i.e.: oncological, traumatic, osteoradionecrosis, etc..); (4) Considering different type of free flaps (i.e.: antero-lateral thigh free flap, fibula free flap, forearm free flap, etc..), and their combination for defect reconstruction; (5) Clearly describing postoperative early and late complications onset (i.e.: partial and total flap necrosis, venous congestion, wound dehiscence and fistula occurrence, local infection, donor site complications), and specifying the need of revision surgery. Articles reporting hypo-pharyngeal and laryngeal defects reconstruction, and those cases managed by composite and/or chimeric flaps alone without simultaneous double free flap reconstruction were excluded from the analysis.

Abstracts were independently selected and analyzed by two different investigators; papers that fulfilled inclusion and exclusion criteria were identified, and a first qualitative and descriptive analysis of the selected articles was carried on; then, only publications clearly describing their aim and objectives, their inclusion and exclusion criteria, with clear or detachable statistical data, reporting success rates, and well describing the surgical techniques and post-operative complications, were included in our systematic review. Eligibility for inclusion was separately assessed, and in case of doubt, discussed and decided by consensus. All the included papers were graded using the NICE scoring scale for retrospective case series (Available at: http:// www.nice.org.uk/nicemedia/pdf/Appendix_04_qualityofcase_series_ form_preop.pdf) (Table 1).

For statistical analysis, Fisher's exact test was used for statistical analysis of categorical data, where a value of $p<0.05$ was considered significant, by using STATA version 13 (StataCorp. 2013. Stata Statistical Software: Release 13. College Station, TX: StataCorp LP).

\section{Results}

We selected a total of 179 relevant titles starting from 2004 to the search date by means of the criteria described above. After the
Table 1

Quality assessment for case series.

Quality assessment for case series

Case series collected in more than 1 center (i.e.: a multicentric study) Is the hypothesis/aim/objective of the study clearly described? Are the inclusion and exclusion criteria (case definition) clearly reported? Is there a clear definition of the outcomes reported?

Were data collected prospectively?

Is there an explicit statement that patients were recruited consecutively? Are the main findings of the study clearly described?

Are outcomes stratified (i.e.: by disease type, flaps management and outcomes, patient characteristics, complications)?

exclusion of duplicate studies and foreign language texts, 144 articles were screened based on their title and abstracts by two authors independently. 18 articles were considered as potential candidates and the full manuscripts were obtained for review; 2 out of them lacked a clear discrimination between single and double free flaps and they were consequently excluded. Ultimately, a total amount of 16 studies were included in our systematic review, as showed by the PRISMA flow diagram (Fig. 1). 14 out of the selected 16 articles were case series (only one out of them included less than 10 cases) [4,5,8-19], while the remaining two articles were case reports $[20,21]$. We tested all of the case series by NICE scoring scale, and 5 out of the 14 articles collected a score $\geq 6$ and were considered as good quality studies; on the other hand, 8 papers scored four or five, and only one paper scored three, as shown in Table 2. None of the selected articles was a multicentric either a prospective work.

We recorded a total of 982 simultaneous double free flaps performed in 491 patients for complex oral-mandibular defects reconstruction, over the last fifteen years. Defect reconstruction after oncological ablative surgery represented the $92.3 \%$ of the cases (453 patients), whilst the other main indications were given in case of mandibular osteoradionecrosis and post-treatment trismus onset, $6.9 \%$ and $0.8 \%$, respectively. We divided the patients into three groups based on previous treatments. This data was reported in 10 out of 16 studies and was available for a total of

277 patients (56.4\%). The first group included 144 patients $(52.0 \%)$ who underwent a double-flap reconstruction as primary treatment. 48 patients (17.3\%) already underwent a previous surgery for head and neck pathology, and thus were considered as a secondary surgery group for recurrence or for a secondary tumor. The third group included a total of 94 patients (33.9\%) who underwent salvage surgery: a surgical operation performed after a primary RT or CRT treatment due to tumor persistence or recurrence. It is important to underlay that 9 patients underwent a previous surgery combined with adjuvant RT. In 5 studies, these data were not available for a total of 214 patients (43.6\%).

Moreover, only four patients of them had defect reconstruction as second step procedure (Table 2).

There was a wide variety of flap combinations, but among all, the most common associations were represented by the FFF with the ALT (274 patients) and the FFF combined with the RFF (107 patients), reported in the $55.8 \%$ and $21.8 \%$ of the cases, respectively (Table 3 ).

Data describing extension of the defect and tissue type involved were available in only 151 patients (30.7\%). Defects were classified based on the type of tissue involved (bone, intraoral mucosa and facial skin). Bone defects included those involving the mandible, and/or the maxilla, and/or the skull base. Intraoral defects included the oral mucosa in all of its different subsites and the tongue. Patients were then divided into groups based on the combination of tissue to be reconstructed: bone in association with intraoral defect, bone with facial skin defect, bone with both facial skin and intraoral defect, facial skin, and intraoral defect. Patients who underwent double flap due to bone defect following osteoradionecrosis or plaque exposure, and those undergoing surgery for dynamic tongue reconstruction were also 


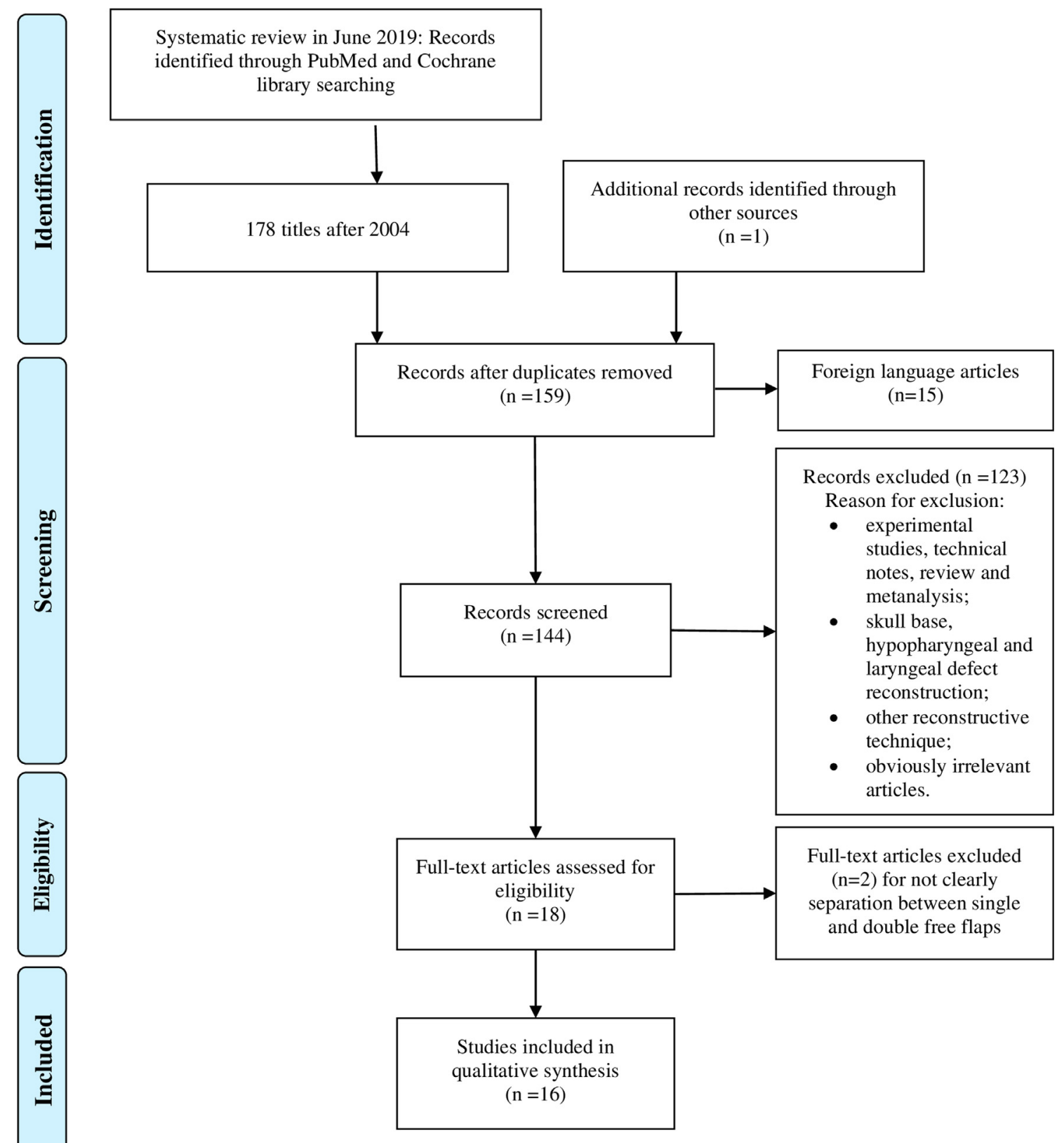

Fig. 1. This flow-chart illustrates the process that was used to select articles for the review.

considered in distinct groups (Table 4).

Data of the size of the defect to be reconstructed were available in 97 patients with a medium value or an interval of the measure of the defect size reported for the whole study group. In 3 out of the 16 studies, the length of the bone defect varied from $6 \mathrm{~cm}$ up to $14 \mathrm{~cm}$. Offodile et al. [4] reported a medium bone defect length of $10.3 \mathrm{~cm}$. Regarding the volume of oral mucosa and skin defect, data was available in 7 studies and they ranged from $24 \mathrm{~cm}^{2}$ to $256 \mathrm{~cm}^{2}$, and from $30 \mathrm{~cm}^{2}$ to $216 \mathrm{~cm}^{2}$, respectively. No studies mentioned the length of vascular pedicles. Vein grafts were necessary in a total of 14 cases ( 2 in the study conducted by Brinkman, 4 described by Lin and 8 by Yazar) $[8,14,19]$.

Most of the authors preferred a two équipes approach and they declared a mean operative time, ranging between 600 and $865 \mathrm{~min}$, including both ablative and reconstructive surgery when simultaneously performed.

Post-operative complications and flap success rate were available in all of the studies, and they have been included and summarized in
Table 5. Total flap loss due either to artery thrombosis or venous congestion, occurred in 27 patients with a final total double flap failure rate of 5.5\%. On the other hand, partial flap loss was observed in 24 patients (4.9\%). It was not possible to evaluate differences between the 3 groups of patients, concerning the data regarding previous treatments, duration of hospitalization, and flap failure or complications, because of the lack of these information in all examined papers. In future studies, it will be interesting to evaluate rate of flap failure and surgical complications between patients who underwent primary surgery and salvage surgery, even if available data in international literature don't show important differences in flap success rate for previously irradiated patients.

Revision surgery was needed in 62 patients (12.6\%), and among them, 29 patients experienced venous thrombosis, 7 patients had artery thrombosis, one case due to a postoperative bleeding, and the other one due to a carotid blow-out; the remaining 26 causes for revision surgery have not been clarified by the authors. Median hospital stay was reported in 9 articles ranging between 11 and 28 days. 
Table 2

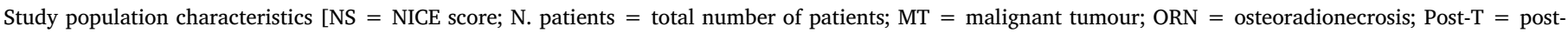
treatment trismus; PT = primary treatment; PS = previous surgery; SS = salvage surgery; NA not available].

\begin{tabular}{|c|c|c|c|c|c|c|c|c|}
\hline \multirow[t]{2}{*}{ Articles } & \multirow[t]{2}{*}{ NS } & \multirow[t]{2}{*}{ N. patients } & \multicolumn{3}{|c|}{ Aetiology } & \multicolumn{3}{|c|}{ Surgical procedure } \\
\hline & & & MT & ORN & Post-T & PT & PS & SS \\
\hline Offodile et al., 2017 [4] & 6 & 33 & 33 & 0 & 0 & 31 & 0 & 2 \\
\hline Stalder et al., 2019 [5] & 6 & 21 & 11 & 10 & 0 & 6 & 0 & 15 \\
\hline Brinkman et al., 2018 [8] & 6 & 42 & 42 & 0 & 0 & 35 & 0 & 7 \\
\hline Sokoya et al., 2018 [9] & 3 & 45 & 45 & 0 & 0 & 14 & 0 & 31 \\
\hline Rommel et al., 2017 [10] & 5 & 15 & 0 & 15 & 0 & 10 & 0 & 5 \\
\hline Mo et al., 2014 [11] & 5 & 12 & 12 & 0 & 0 & 9 & NA & NA \\
\hline Balasubramani et al., 2012 [12] & 6 & 21 & 21 & 0 & 0 & 10 & 0 & 11 \\
\hline Guillemaud et al., 2009 [13] & 4 & 35 & 32 & 0 & 2 & NA & NA & NA \\
\hline Lin et al., 2008 [14] & 5 & 56 & 56 & 0 & 0 & NA & NA & NA \\
\hline Andrades et al., 2008 [15] & 5 & 18 & 18 & 0 & 0 & NA & NA & NA \\
\hline Hanasono et al., 2008 [16] & 6 & 38 & 34 & 4 & 0 & 25 & 0 & 13 \\
\hline Posch et al., 2007 [17] & 5 & 12 & 7 & 5 & 0 & 4 & 8 & 8 \\
\hline Jeng et al., 2004 [18] & 5 & 10 & 10 & 0 & 0 & NA & NA & NA \\
\hline Yazar et al., 2005 [19] & 5 & 130 & 130 & 0 & 0 & NA & 38 & NA \\
\hline Chou et al., 2017 [20] & NA & 1 & 0 & 0 & 2 & 0 & 1 & 1 \\
\hline Henn et al., 2015 [21] & NA & 2 & 2 & 0 & 0 & 0 & 1 & 1 \\
\hline
\end{tabular}

Table 3

Flaps choice.

\begin{tabular}{|c|c|}
\hline Flap choice & Number of flaps \\
\hline \multicolumn{2}{|l|}{ flaps } \\
\hline fibula & 423 \\
\hline alt & 297 \\
\hline rfff & 140 \\
\hline latissimus dorsi & 14 \\
\hline rectus bdominis & 30 \\
\hline iliac crest & 10 \\
\hline scapula (circumflex scapular artery) & 6 \\
\hline $\begin{array}{l}\text { other (UFFF, tibialis anterior, serratus, aMT, vlf, gracilis, } \\
\text { gastro omental, dorsalis pedis }\end{array}$ & 16 \\
\hline not available & 46 \\
\hline Total & 982 \\
\hline \multicolumn{2}{|l|}{$\begin{array}{l}\text { Combinations of flaps } \\
\text { fibula with: }\end{array}$} \\
\hline - alt & 274 \\
\hline$-\mathrm{rfff}$ & 107 \\
\hline - rectus abdominis & 22 \\
\hline - latissimus & 7 \\
\hline - uFFF & 2 \\
\hline - vlf & 2 \\
\hline - Other (amt, FFF, anterior tibial, inf epigastric, serratus) & 5 \\
\hline \multicolumn{2}{|l|}{ - ALT with: } \\
\hline$-\mathrm{rfff}$ & 7 \\
\hline - alt & 5 \\
\hline - UFFF & 1 \\
\hline - rectus abdominis & 1 \\
\hline - scapula & 1 \\
\hline \multicolumn{2}{|l|}{ - rfff or orfff with: } \\
\hline - latissimus & 6 \\
\hline - rectus abdominis & 5 \\
\hline - RFFF & 2 \\
\hline - iliac crest & 9 \\
\hline \multicolumn{2}{|l|}{ - other } \\
\hline - serratus + rectus abdominis & 1 \\
\hline - scapula + dorsalis pedis & 2 \\
\hline - iliac crest + scapula & 2 \\
\hline - gracilis + gastro-omental & 2 \\
\hline
\end{tabular}

\section{Discussion}

Head and neck reconstruction can be challenging in patients with extensive tumor, prior surgery, recurrences, or history of radiotherapy. Free tissue transfers have several advantageous characteristics [22,23]. As a result, free tissue transfer has been used with increasing frequency, despite greater cost associated with raised operative times, and longer hospitalization.

In this setting, the actual issue is to address this type of challenging surgery to the best receiving and suitable patient [24-29].

In this study, we sought to review recent outcomes of head and neck reconstruction using simultaneously double donor tissues and to determine their clinical advantages, by analyzing their indications and limits in order to introduce an up-to-date and novel practical algorithm resuming their clinical application. Despite clinical characteristics and preoperative predictive factors were not homogenously available from the 16 included studies, surgical indications, perioperative factors, and technical details, together with postoperative complications onset and outcomes were clearly described, collected, and analyzed for all of the 491 patients who underwent complex oral-mandibular defects reconstruction.

Our results confirmed that the vast majority of double free flaps found surgical indication in case of advanced head and neck stage disease requiring wide ablative surgery (92.3\%), and causing composite defect of the middle-inferior third of the face. On the other hand, functional indications were represented by $7.7 \%$ of the cases, only. Moreover, among the 453 head and neck patients who underwent ablative surgery, $51.2 \%$ had salvage procedure or second surgery, confirming how previous head and neck treatments, either surgery or radiotherapy, do not represent absolute contraindication to even such complex microsurgical procedures.

At this point, critical consideration for reconstructive alternatives would include composite or chimeric free flaps indications. It has reported that defects with a "through-and-through" soft tissue component involving both intraoral lining and external skin, presents a better inset outcome with intrinsic chimeric flap reconstruction than with composite flap reconstruction. This finding is supported by the unique characteristics of chimeric flaps that comprise various tissue types on separate vascular leashes naturally converging to a single vascular pedicle, allowing for a wide degree of freedom of component inset. On the contrary, composite flaps do not offer this flexibility, because the flap components are not dissected out on their individual pedicles [30-34].

Given the advantages of having more mobile and custom flap components, surgeons have experimented with the concept of anastomosing one flap to another to allow greater degrees of movement between the components since 1990 [35], but, later, controversies have risen against their routine application $[36,37]$. Consequently, there still remains some scenarios in which 2 free flaps might be necessary. One scenario is when there are large soft tissue needs in addition to a large, 
Table 4

Flaps choice regarding anatomical sites involved by the pathology, tissue type and defect dimension.

\begin{tabular}{|c|c|c|}
\hline & Flap Choice & Number \\
\hline \multicolumn{3}{|l|}{ anatomic subsites } \\
\hline \multirow[t]{6}{*}{ Bone + intraoral defect } & - $\mathrm{FFF}+\mathrm{RFFF}$ & 13 \\
\hline & - FFF + ALT & 10 \\
\hline & - FFF + rectus & 2 \\
\hline & - $\mathrm{SFF}+\mathrm{LDF}$ & 1 \\
\hline & - $\mathrm{ALT}+$ rectus & 1 \\
\hline & - $\mathrm{RFF}+$ rectus & 1 \\
\hline bone + Facial skin & - $\mathrm{FFF}+\mathrm{RFFF}$ & 1 \\
\hline \multirow[t]{5}{*}{ bone + intraoral defect + facial skin } & $\begin{array}{l}\text { - } \mathrm{FFF}(+ \text { skin } \\
\text { paddle })+\mathrm{ALT}\end{array}$ & 75 \\
\hline & - $\mathrm{FFF}+\mathrm{RFFF}$ & 8 \\
\hline & - ORFFF + ALT & 1 \\
\hline & - FFF + Serratus & 1 \\
\hline & - $\mathrm{ALT}+\mathrm{RFFF}$ & 1 \\
\hline \multirow[t]{3}{*}{ Intraoral defect + facial skin } & - $\mathrm{ALT}+\mathrm{RFFF}$ & 4 \\
\hline & - RFFF + RFFF & 2 \\
\hline & - ALT + Serratus & 1 \\
\hline \multirow{4}{*}{$\begin{array}{l}\text { exposed plate/necrotic bone }+ \text { soft } \\
\text { tissue defect }\end{array}$} & - $\mathrm{FFF}+\mathrm{RFFF}$ & 8 \\
\hline & - $\mathrm{FFF}+\mathrm{ALT}$ & 4 \\
\hline & - FFF + VLF & 2 \\
\hline & $\bullet \mathrm{FFF}+\mathrm{LDF}$ & 1 \\
\hline dynamic tongue reconstruction & - Gracilis + gastro-omental & 2 \\
\hline \multirow[t]{3}{*}{ hypofarynx + skin } & - jejunum + RFFF & 10 \\
\hline & - jejunum + UFFF & 1 \\
\hline & - rectus + RFFF & 1 \\
\hline Total & & 151 \\
\hline
\end{tabular}

Table 5

Post-operative complications summary.

\begin{tabular}{ll}
\hline Complications & Number of patients (\%) \\
\hline EARLY POST OPERATIVE COMPLICATIONS & \\
- TOTAL FLAP LOSS & $27(5.5)$ \\
- PARTIAL FLAP LOSS & $24(4.9)$ \\
- WOUND HEALING IMPAIRMENT & $68(13.8)$ \\
- Wound infection & $23(4.7)$ \\
- Dehiscence & $15(3.1)$ \\
- Hematoma & $19(3.9)$ \\
- Seroma & $4(0.8)$ \\
- Abscess & $6(1.2)$ \\
- Osteomyelitis & $1(0.2)$ \\
- FISTUALE & $22(4.5)$ \\
- donor site complications & $9(1.8)$ \\
- NEED FOR REVISION SURGERY & $62(12.6)$ \\
- SYSTEMIC COMPLICATIONS & $31(6.3)$ \\
- Death for cardiac causes ore stroke & $5(1.0)$ \\
- Death for respiratory arrest & $2(0.4)$ \\
- Pneumonia & $4(0.8)$ \\
- Respiratory failure & $12(2.4)$ \\
- Cardiac complications & $3(0.6)$ \\
- DVT or coagulopathy & $4(0.8)$ \\
- Severe hypothyroidism & $1(0.2)$ \\
LONG TERM POST OPERATIVE COMPLICATIONS & \\
- BONE OR PLATE EXPOSURE & $15(3.0)$ \\
- OSTEORADIONECROSIS & $4(0.8)$ \\
- ORAL INCOMPETENCE & $4(0.8)$ \\
- limitation of mouth opening & $3(0.6)$ \\
- pharryngoesofageal stenosis & $1(0.2)$ \\
TOTAL patients 491 & $1(0.2)$ \\
\hline & $271(55.2)$ \\
& \\
\hline & \\
\hline
\end{tabular}

complex bony defect accordingly to our results. Some previous reports on double free flap reconstruction, reflected that the range of surface area covered by the intrinsic chimeric flap use was $5-390 \mathrm{~cm}^{2}$ (average $135 \mathrm{~cm}^{2}$ ), whereas when two flaps were used simultaneously, defect extension ranged between 225 and $500 \mathrm{~cm}^{2}$ (average $350 \mathrm{~cm}^{2}$ ) [38-41]. Even when a single intrinsic chimeric flap is contraindicated for patient's related reasons, including for example obesity or extensive donor site morbidity, reconstruction with double free flaps even for less extensive defects might be considered.

Unfortunately, only $30.7 \%$ of our study population had a clear description of the defect extension and of its involved tissues, but it has come out, that the vast majority of the treated defect (86 out of 151 . $57 \%$ ), were represented by composite tissues defect enclosing bone, skin, and intraoral mucosal lack at the same time, where 75 of them $(87.2 \%)$ were reconstructed by the use of FFF plus ALT with skin paddle. This confirms that the combination of FFF and ALT represents the most common double free flap association used by surgeons (55.8\%), followed by FFF combined with RFFF (21.8\%). Since 381 out of 491 patients had at least FFF transfer, we can affirm that bone tissue lost, combined with intraoral defect with/without skin removal, is the most frequent reason for considering indication to double free flaps use.

Concerning operative time, double free flaps might be quicker due to the theoretical possibility of a 3-team approach when compared to a chimeric flap that can be harvested after tumor resection. According to literature [23], we found a mean operative time ranging between 10 and $14.4 \mathrm{~h}$, which might justify to privilege double flaps reconstruction, against chimeric or composite ones for which some authors reported a mean operative time of 17 and $14 \mathrm{~h}$, respectively [42]. Another possible argument against using the intrinsic chimeric flap is a steep learning curve, where flap elevation and inset require a higher level of expertise, and strong microsurgical knowledge. However, intrinsic chimeric flap, compared to double free flaps, in addition to limiting donor site morbidity to one single site, preserves other potential future donor sites in case of recurrence or to manage a complication. It also offers the advantage of a single microvascular anastomosis when there is often a paucity of recipient vessels. Accordingly, it is well known that the choice of recipient vessels can directly affect the indications and outcomes. Although the choice of flaps with long pedicle and the choice of recipient neck vessels outside the zone of injury can be effective in overcoming this problem, in some cases extension to the flap pedicle length is required. Unfortunately, in our case series there was no mention about pedicle length, but we found some information about vein graft (VG) use. Indeed, in head and neck free flap reconstruction, few studies in literature accounts for the use of VG, thus leading to controversial outcomes [43-45]. Surgeons should be aware that the longer the vein graft, the greater is the risk of flap compromise and flap loss. We counted only 14 patients $(2.8 \%)$ who had VG, out of the 491 patients of our study population.

No mention of intraoperative protocols regarding vessel selection, geometry, and number of vessels anastomosed, including mechanical coupling devices use, in attempts to improve operative time, decreased flap ischemia time, have been found in the 16 selected articles. Even the difference between the number of veins to anastomose, which represents a topic of debate, or the concept of goal-directed hemodynamic therapy (GDHT), have been deepened.

Flap elevation and inset, together with type of ablative surgery, affect operative time, which in turn might affect postoperative outcome. Above all, the key to free flap success is maintaining the patency of the anastomosis, but our 16 selected articles did not mention neither recommend specific prophylactic intra- and peri- operative indications.

Above all, close monitoring during the first $24-48 \mathrm{~h}$ after surgery remains the most critical time window for identifying an impending flap failure [46-48], and we found an overall postoperative complication rate of $55.2 \%$, similarly to those percentages reported for chimeric $(51 \%)$ and composite $(60 \%)$ flaps use for complex oro-mandibular defect reconstruction [42], and to other rates cited previously, ranging from $48 \%$ to $71 \%[49,50]$. The vast majority of the recorded complications had an early postoperative onset (89.3\%), but only 62 out the 491 patients $(12.6 \%)$ required a microsurgical revision against the $19 \%$ and $17 \%$ of re-intervention incidence for chimeric and composite flaps, respectively, according to Silva AK et al. [42]. Above all, the wound infection was the most common postoperative complication, with an incidence of $13.8 \%$. Our overall free tissue transfer failure rate was of 


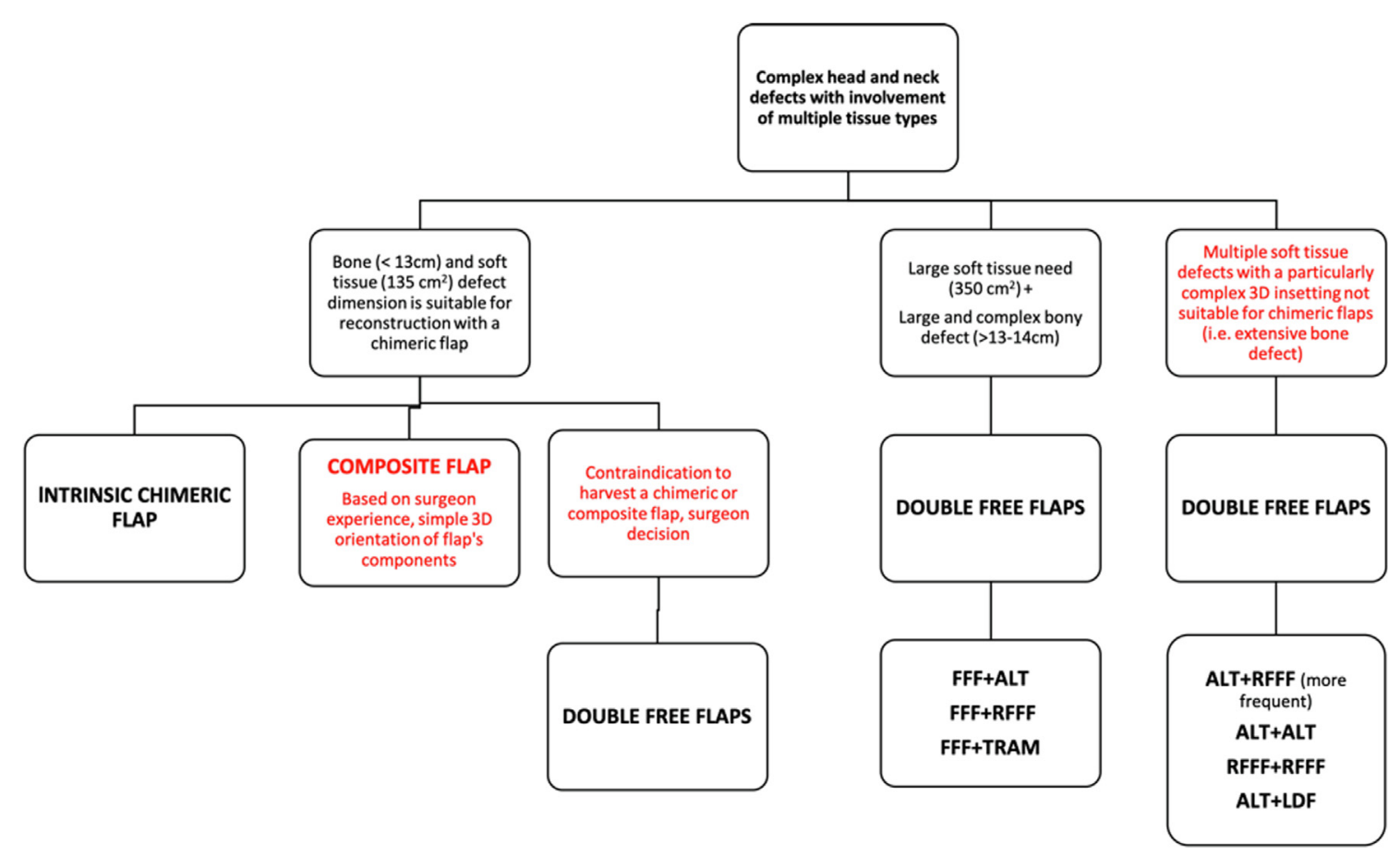

Fig. 2. Double free flap recommended combination in case of complex and composite oral cavity and oropharyngeal defect reconstruction.

$5.5 \%$, which is quite similar to single free flap failure rate reported by Sweeny $\mathrm{L}$ et al. to be of $4 \%$ [23], and it is much lower that general range reported in literature (1-15\%) [51-56].

Mean hospital stay is influenced by health system organization and is generally shorter in a private setting. As expected, hospitalization was longer for patients who developed a postoperative complication ( $p<0.0001)$. Generally speaking, double free flap reconstructions does not prolong hospital stay per se, but long hospitalization is related to the big composite resections that put patients at risk for higher complications rate.

\section{Conclusions}

Head and neck reconstruction can be challenging in patients with extensive tumor, prior surgery, recurrences, or history of radiotherapy According to our results, two free flaps might be necessary when the defect contains both a large, complex bony defect and large soft tissue needs; Fig. 2 reports our flowchart of double free flap combination that we recommend in case of complex and composite oral cavity and oropharyngeal defect reconstruction. Even if they are related to high incidence of complications, they seem to be worth it because of better post-operative quality of life, compare to other surgical options. Another reconstructive technique, such as the use of chimeric flaps, seems to be a good alternative, but may relate to a prolonged intraoperative time. However, there were limitations of this study including retrospective design, lack of quality of life data, and absence of data on medical comorbidities and intraoperative protocols and postoperative monitoring. Unfortunately, only 3 papers reported functional outcomes, whose results were heterogeneous and not comparable to draw a whole description of their potential advantages. Furthermore, we were unable to separate the reconstructive surgical time from the ablative surgical time, limiting the conclusions which could be made.

Consequently, homogeneous studies are needed to better understand feasibility and complication rate of wide head and neck resection and double flaps reconstruction.

\section{Declaration of Competing Interest}

None declared.

\section{Acknowledgements}

This research did not receive any specific grant from funding agencies in the public, commercial, or not-for-profit sectors.

We thank Doctor Gabriella Carollo for providing language help.

\section{References}

[1] Chen CL, Zenga J, Roland LT, Pipkorn P. Complications of double free flap and free flap combined with locoregional flap in head and neck reconstruction: a systematic review. Head Neck 2018;40:632-46.

[2] Wallace CG, Tsao CK, Wei FC. Role of multiple free flaps in head and neck reconstruction. Curr Opin Otolaryngol Head Neck Surg 2014;22:140-6.

[3] Wei FC, Yazar S, Lin CH, Cheng MH, Tsao CK, Chiang YC. Double free flaps in head and neck reconstruction. Clin Plast Surg 2005;32:303-8.

[4] Offodile AC, Lin JA, Chang KP, Abdelrahman M, Kou HW, Loh CYY, et al. Anterolateral thigh flap combined with reconstruction plate versus double free flaps for composite mandibular reconstruction: a propensity score-matched study. Ann Surg Oncol 2018;25:829-36.

[5] Stalder MW, Mundinger GS, Bartow M, Pharo A, Patterson C, Sharma S, et al. Single versus simultaneous double free flaps for head and neck reconstruction: comparison of flap outcomes and donor-site morbidity. Ann Plast Surg 2019;82:184-9.

[6] Yazar S, Wei FC, Chen HC, Cheng MH, Huang WC, Lin CH, et al. Selection of recipient vessels in double free-flap reconstruction of composite head and neck defects. Plast Reconstr Surg 2005;115:1553-61.

[7] Abouyared M, Katz AP, Ein L, Ketner J, Sargi Z, Nicolli E, et al. Controversies in free tissue transfer for head and neck cancer: a review of the literature. Head Neck 2019;41:3457-63.

[8] Brinkman JN, Kambiz S, de Jong T, Mureau MAM. Long-term outcomes after double free flap reconstruction for locally advanced head and neck cancer. J Reconstr Microsurg 2019;35:66-73.

[9] Sokoya M, Bahrami A, Vincent A, Kadakia S, Inman J, Saman M, et al. Preoperative radiation and complication rates after double free flap reconstruction of head and neck cancer. Am J Otolaryngol. 2018;39:558-60.

[10] Rommel N, Kesting MR, Rohleder NH, Wolff KD, Weitz J. Surgical management of severe osteoradionecrosis of the mandibular bone by using double free flap reconstruction. J Craniomaxillofac Surg 2018;46:148-54.

[11] Mo KW, Vlantis A, Wong EW, Chiu TW. Double free flaps for reconstruction of complex/composite defects in head and neck surgery. Hong Kong Med J 2014;20:279-84.

[12] Balasubramanian D, Thankappan K, Kuriakose MA, Duraisamy S, Sharan R, Mathew $\mathrm{J}$, et al. Reconstructive indications of simultaneous double free flaps in the head and 
neck: a case series and literature review. Microsurgery 2012;32:423-30.

[13] Guillemaud JP, Seikaly H, Cote DW, Barber BR, Rieger JM, Wolfaardt J, et al. Double free-flap reconstruction: indications, challenges, and prospective functional outcomes. Arch Otolaryngol Head Neck Surg 2009;135:406-10.

[14] Lin PY, Kuo YR, Chien CY, Jeng SF. Reconstruction of head and neck cancer with double flaps: comparison of single and double recipient vessels. J Reconstr Microsurg 2009;25:191-5.

[15] Andrades P, Bohannon IA, Baranano CF, Wax MK, Rosenthal E. Indications and outcomes of double free flaps in head and neck reconstruction. Microsurgery 2009;29:171-7.

[16] Hanasono MM, Weinstock YE, Yu P. Reconstruction of extensive head and neck defects with multiple simultaneous free flaps. Plast Reconstr Surg 2008;122:1739-46.

[17] Posch NA, Mureau MA, Dumans AG, Hofer SO. Functional and aesthetic outcome and survival after double free flap reconstruction in advanced head and neck cancer patients. Plast Reconstr Surg 2007;120:124-9.

[18] Jeng SF, Kuo YR, Wei FC, Su CY, Chien CY. Reconstruction of extensive composite mandibular defects with large lip involvement by using double free flaps and fascia lata grafts for oral sphincters. Plast Reconstr Surg 2005;115:1830-6.

[19] Yazar S. Selection of recipient vessels in microsurgical free tissue reconstruction of head and neck defects. Microsurgery 2007;27:588-94.

[20] Chou C, Chen CC, Lai CS, Lin SD, Kuo YR. Simultaneous double free radial forearm flaps combined with coronoidectomy and myotomy to release bilateral severe trismus: a case report. Microsurgery 2017;37:831-5.

[21] Henn D, Nissen A, Menon N, Lee GK. Restoration of oral competence in double free flap reconstructions of massive lower facial defects with fascia lata slings - Case series and review of the literature. Case Reports Plast Surg Hand Surg 2015;2:67-72.

[22] Gao LL, Basta M, Kanchwala SK, Serletti JM, Low DW, Wu LC. Cost-effectiveness of microsurgical reconstruction for head and neck defects after oncologic resection. Head Neck 2017;39:541-7.

[23] Sweeny L, Rosenthal EB, Light T, Grayson J, Petrisor D, Troob SH, et al. Outcomes and cost implications of microvascular reconstructions of the head and neck. Head Neck 2019;41:930-9.

[24] Nao EEM, Dassonville O, Chamorey E, Possonnet G. Head and neck free-flap reconstruction in the elderly. Eur Ann Otorhinolaryngol Head Neck Dis 2011;128:47-51.

[25] Peters TTA, Post SF, van Dijk BAC, Roodenburg JL, van der Laan BF, Werker PM, et al. Free flap reconstruction for head and neck cancer can be safely performed in both young and elderly patients after careful patient selection. Eur Arch Otorhinolaryngol 2015;272:2999-3005.

[26] Lee MK, Blackwell KE, Kim B, Nabili V. Feasibility of microvascular head and neck reconstruction in the setting of calcified arteriosclerosis of the vascular pedicle. JAMA Facial Plast Surg 2013;15:135-40.

[27] Kuri M, Nakagawa M, Tanaka H, Hasuo S, Kishi Y. Determination of the duration of preoperative smoking cessation to improve wound healing after head and neck surgery. Anesthesiology 2005;102:892-6.

[28] Rosado P, Cheng HT, Wu CM, Wei FC. Influence of diabetes mellitus on postoperative complications and failure in head and neck free flap reconstruction: a systematic review and meta-analysis. Head Neck 2014;37:615-8.

[29] Offodile AC, Chou HY, Lin JA, Loh CYY, Chang KP, Aycart MA, et al. Hyperglycemia and risk of adverse outcomes following microvascular reconstruction of oncologic head and neck defects. Oral Oncol 2018;79:15-9.

[30] Agarwal JP, Agarwal S, Adler N, Gottlieb LJ. Refining the intrinsic chimera flap: a review. Ann Plast Surg 2009;63:462-7.

[31] Chang EI, Yu P. Prospective series of reconstruction of complex composite mandibulectomy defects with double island free fibula flap. J Surg Oncol 2017; 116:258-62

[32] Leclère FM, Bosc R, Temam S, Leymarie N, Mirghani H, Sarfati B, et al. Reconstruction of large mandibulofacial defects with the composed double skin paddle fibula free flap: a review of 32 procedures. Laryngoscope 2014:124:1336-43.

[33] Potter JK, Lee MR, Oxford L, Wong C, Saint-Cyr M. Proximal peroneal perforator in dual-skin paddle configuration of fibula free flap for composite oral reconstruction. Plast Reconstr Surg 2014;133:1485-92.

[34] Kannan RY, Mathur BS, Tzafetta K. Single flap reconstruction for complex oro-facial defects using chimeric free fibular flap variants. J Plast Reconstr Aesthet Sur 2013:66:358-63.

[35] Sanger JR, Matloub HS, Yousif NJ. Sequential connection of flaps: a logical approach to customized mandibular reconstruction. Am J Surg 1990;160:402-4.

[36] Wei FC, Demirkan F, Chen HC, Chen IH. Double free flaps in reconstruction of extensive composite mandibular defects in head and neck cancer. Plast Reconstr Surg 1999;103:39-47.

[37] Gabr E, Kobayashi MR, Salibian AH, Armstrong WB, Sundine M, Calvert JW, et al. Mandibular reconstruction: are two flaps better than one? Ann Plast Surg 2004;52:31-5.

[38] Lee JT, Hsu H, Wang CH, Cheng LF, Sun TB, Huang CC, et al. Reconstruction of extensive composite oromandibular defects with simultaneous free anterolateral thigh fasciocutaneous and fibular osteocutaneous flaps. J Reconstr Microsurg 2010;26:145-51.

[39] Wei FC, Celik N, Chen H, Cheng MH, Huang WC. Combined anterolateral thigh flap and vascularized fibula osteoseptocutaneous flap in reconstructive of extensive composite mandibular defects. Plast Reconstr Surg 2002;109:45-52.

[40] Ao M, Asagoe K, Maeta M, Nakagawa F, Saito R, Nagase Y. Combined anterior thigh flaps and vascularised fibular graft for reconstruction of massive composite oromandibular defects. Br J Plast Surg 1998;51:350-5.

[41] Nakatsuka T, Haril K, Yamada A, Ueda K, Ebihara S. Dual free flap transfer using forearm flap for mandibular reconstruction. Head Neck 1992;14:452-8.

[42] Silva AK, Humphries LS, Maldonado AA, Gottlieb LJ. Chimeric vs composite flaps for mandible reconstruction. Head Neck 2019;41:1597-604.

[43] Bullocks J, Naik B, Lee E, Hollier L. Flow-through flaps: a review of current knowledge and a novel classification system. Microsurgery 2006;26:439-49.

[44] Angel MF, Chang B, Clark N, Wong L, Ringelman P, Manson PN. Further clinical use of the interposition arteriovenous loop graft in free tissue transfers. Microsurgery 1993;14:479-81.

[45] Di Taranto G, Chen SH, Elia R, Sitpahul N, Chan JCY, Losco L. Outcomes following head neck free flap reconstruction requiring interposition vein graft or vascular bridge flap. Head Neck 2019;41:2914-20.

[46] Hosein RC, Cornejo A, Wang HT. Postoperative monitoring of free flap reconstruction: a comparison of external Doppler ultrasonography and the implantable Doppler probe. Plast Surg 2016;24:11-9.

[47] Guillemaud JP, Seikaly H, Cote D, Allen H, Harris J. The implantable Cook-Swartz Doppler probe for postoperative monitoring in head and neck free flap reconstruction. Arch Otolaryngol Head Neck Surg 2008;134:729-34.

[48] Wax MK. The role of the implantable Doppler probe in free flap surgery. Laryngoscope 2014;124:S1-12.

[49] Ettinger KS, Arce K, Lohse CM, Peck BW, Reiland MD, Bezak BJ, et al. Higher perioperative fluid administration is associated with increased rates of complications following head and neck microvascular reconstruction with fibular free flaps. Microsurgery 2017;37:128-36.

[50] Corbitt C, Skoracki RJ, Yu P, Hanasono MM. Free flap failure in head and neck reconstruction. Head Neck 2014;36(10):1440-5.

[51] Frederick JW, Sweeny L, Carroll WR, Rosenthal EL. Microvascular anastomotic coupler assessment in head and neck reconstruction. Otolaryngol Head Neck Surg 2013;149:67-70.

[52] Las DE, de Jong T, Zuidam JM, Verweij NM, Hovius SE, Mureau MA. Identification of independent risk factors for flap failure: a retrospective analysis of 1530 free flaps for breast, head and neck and extremity reconstruction. J Plast Reconstr Aesthet Surg 2016;69:894-906.

[53] le Nobel GJ, Higgins KM, Enepekides DJ. Predictors of complications of free flap reconstruction in head and neck surgery: analysis of 304 free flap reconstruction procedures. Laryngoscope 2012;122:1014-9.

[54] Nakatsuka T, Harii K, Asato H, Takushima A, Ebihara S, Kimata Y, et al. Analytic review of 2372 free flap transfers for head and neck reconstruction following cancer resection. J Reconstr Microsurg 2003;19:363-8. discussion 369.

[55] Suh JD, Sercarz JA, Abemayor E, Calcaterra TC, Rawnsley JD, Alam D, et al. Analysis of outcome and complications in 400 cases of microvascular head and neck reconstruction. Arch Otolaryngol Head Neck Surg 2004;130:962-6.

[56] Yu P, Chang DW, Miller MJ, Reece G, Robb GL. Analysis of 49 cases of flap compromise in 1310 free flaps for head and neck reconstruction. Head Neck 2009;31(1):45-51. 